\title{
Current thinking on malignant salivary gland neoplasms
}

\author{
Rodrigo Arrangoiz ${ }^{*}$, Pavlos Papavasiliuo, David Sarcu, Thomas J. Galloway, John A. Ridge, \\ Miriam Lango
}

Temple University, Fox Chase Cancer Center, 333 Cottman Avenue, Philadelphia USA 19111

\section{Email address:}

rodrigo.arrangoiz@gmail.com(R. Arrangoiz),pavlos.papavasiliuo@fccc.edu(P. Papavasiliuo), david.sarcu@tuhs.temple.edu(D. Sarcu), thomas.galloway@fccc.edu(T. J. Galloway), john.ridge@ffcc.edu(J. A. Ridge), miriam.lango@fccc.edu(M. Lango)

\section{To cite this article:}

Rodrigo Arrangoiz, Pavlos Papavasiliuo, David Sarcu, Thomas J. Galloway, John A. Ridge, Miriam Lango. Current Thinking on Malignant Salivary Gland Neoplasms. Journal of Cancer Treatment and Research. Vol. 1, No. 1, 2013, pp. 8-24.

doi: $10.11648 /$ j.jctr.20130101.12

\begin{abstract}
Malignant salivary gland neoplasms are rare, representing approximately 3\% to $7 \%$ of all head and neck cancers. Contrasting from the more common mucosal head and neck cancers, which, in general, are ascribed to excessive tobacco, alcohol use, and more recently to viral infection, specific carcinogenic factors for malignant salivary gland growths have not been as clearly identified. Histologically, they represent a heterogeneous group of tumors. Forty histologic types of epithelial tumors of the salivary glands have been reported; some are exceedingly rare and may be the topic of only a few case reports. Salivary tumors can arise in the major salivary glands or in one of the minor salivary glands (predominantly mucus secreting glands), which are distributed throughout the upper aerodigestive. Most patients who develop malignant salivary gland tumors are in the sixth or seventh decade of life. FNA should be considered as part of the diagnostic evaluation but due to its varying sensitivities and specificities imaging modalities such as ultrasound, CT scans, and MRI should also be used as diagnostic adjuncts. Surgery is the primary modality for management of these tumors, nontraditional surgical approaches and instrumentation, as well as facial nerve monitoring, can be selectively utilized to try and decrease the morbidity associated with these surgical procedures. Adjuvant treatment is primarily achieved with radiation therapy. Chemotherapy continues to have a palliative role in the management of salivary gland tumors; however, research in this field is trying to identify a therapeutic role for chemotherapy in order to improve overall survival.
\end{abstract}

Keywords: Salivary Gland Tumors, Epidemiology of Salivary Gland Tumors, Types of Salivary Gland Tumors, Diagnosis and Treatment of Salivary Gland Tumors

\section{Introduction}

Malignant salivary gland neoplasm's are relatively rare, representing approximately $3 \%$ to $7 \%$ of all head and neck cancers and accounting for less than $0.5 \%$ of all malignancies diagnosed yearly in the United States [1]. The annual incidence is approximately 2.5 to 3.0 cases per 100,000 individuals [1]. Contrasting from the more common mucosal head and neck cancers, which, in general, are ascribed to excessive tobacco, alcohol use, and more recently to viral infection (HPV), specific carcinogenic factors for malignant salivary gland growths have not been as clearly identified. Exposure to ionizing radiation [2-8] has been implicated as a cause of salivary gland cancer as well as certain occupational exposures, such as, rubber products manufacturing, asbestos mining, plumbing, and some types of woodworking $[9,10]$.
Salivary gland tumors can arise in the major salivary glands (parotid, submandibular, sublingual) or in one of the minor salivary glands (predominantly mucus secreting glands), which are distributed beneath the mucosa throughout the upper aerodigestive tract [11]. Most patients who develop malignant salivary gland tumors are in the sixth or seventh decade of life [12]. Approximately $80 \%$ to $85 \%$ of salivary gland tumors arise in the parotid glands and approximately $75 \%$ to $80 \%$ of these tumors are benign $[13,14]$. Most of these benign tumors are pleomorphic adenomas (benign mixed tumors), representing $60 \%$ to $70 \%$ [1] of all parotid gland tumors, and Warthin's tumors (papillary cystadenoma lymphomatosum), representing 12\% of all benign parotid tumors [13]. With regards to the other major salivary glands, approximately $40 \%$ to $50 \%$ of submandibular tumors are malignant and more than $90 \%$ of tumors arising in the sublingual glands are malignant $[1,14$, 
15]. The ratio of malignant neoplasm's found in the parotid, submandibular, and sublingual glands is estimated to be 40:10:1 respectively [13]. There are 600 to 1000 minor nests of salivary gland cells scattered throughout the upper aerodigestive tract and approximately $75 \%$ to $80 \%$ of tumors arising in these minor salivary glands are malignant $[14,16]$.

Histologically, salivary gland tumors represent the most heterogeneous group of tumors of any tissue in the body[17]. Approximately 40 histologic types of epithelial tumors of the salivary glands have been reported, some are exceedingly rare and may be the topic of only a few case reports [1]. The World Health Organization (WHO) in its 2005 classification of salivary gland tumors described 24 different histologic subtypes [18]. The most common malignant major salivary gland tumor is the mucoepidermoid carcinoma, which comprises about $2.8 \%$ to $15.5 \%$ of all salivary gland neoplasms and approximately $12 \%$ to $35 \%$ of malignant salivary gland neoplasms [1, 19]. For clinical purposes these tumors can be classified according to their malignant potential (propensity to spread) [20]. The most malignant group consists of high-grade mucoepidermoid carcinomas, malignant mixed tumors, adenocarcinomas, and squamous cell carcinomas $[14,20]$. The tumors in this category frequently metastasis to regional lymph nodes as well as to distant sites through a hematogenous route. The intermediate group is made up by the slow growing adenoid cystic carcinoma. They are classified as intermediate tumors despite of their slow growth rate because they tend to invade cranial nerves and spread along them to the base of the brain, and they can also metastasis through hematogenous routes. Low-grade mucoepidermoid carcinomas and acinic cell carcinomas have limited malignant potential and have a better prognosis than highgrade tumors.

\section{Pathogenesis}

Presently there are two theories trying to elucidate the origin of malignant salivary gland tumors $[8,21]$. The more accepted of the two theories is the Reserve Cell Theory [21]. The theory states that salivary gland neoplasms arise from a reserve (or stem) cell of the salivary duct system. The type of neoplasm that will develop will depend on the stage of differentiation of the reserve cell at the time at which the neoplastic transformation occurs (and on the type of reserve cell). The excretory duct reserve cells give rise to mucoepidermoid, squamous cell, and salivary duct carcinoma, while the intercalated duct reserve cells give rise to adenoid cystic and acinic cell carcinoma. The second and less accepted theory is the Multicellular Theory [8]. This theory states that salivary tumors arise from differentiated cells along the salivary gland unit. An example of this theory is that squamous cell carcinoma arises from the excretory duct epithelium and acinic cell carcinoma arises from the acinar cells.

\section{Pathology of Malignant Salivary Gland Neoplasm}

The WHO histologic classification of salivary gland malignancies divide these tumors in two broad categories: low grade and high grade tumors (Table 1) [20]. They represent a heterogeneous group of tumors with a diverse biologic and clinical behavior that have a unique natural history and pattern of spread. We will be discussing some of the most common variants individually in the following section.

\subsection{Mucoepidermoid Carcinoma}

Mucoepidermoid carcinoma (MEC) is the most common malignant neoplasm of the mayor and minor salivary glands. They encompass between $2.8 \%$ to $15.5 \%$ of all salivary gland tumors, among $12 \%$ to $35 \%$ of malignant salivary gland tumors, and among $6.5 \%$ to $41 \%$ of all minor salivary gland tumors, representing the most common type of malignant minor salivary gland tumor in most series [2225]. Approximately half the cases occur in the major salivary glands, $65 \%$ to $80 \%$ of these occur in the parotid, $8 \%$ to $13 \%$ occur in the submandibular gland, and $2 \%$ to $4 \%$ involve the sublingual gland [22-24, 26, 27]. MEC of the minor salivary glands ordinarily arises on the palate, but a number may also be found in the retro molar area, floor of the mouth, buccal mucosa, lip, and tongue [28].

Its prevalence is highest in the fourth to fifth decade of life ( 35 to 65 years of age), with a female preponderance as high as 4:1 [13, 24]. Grossly, the tumor is poorly circumscribed and measures from 3 to $5 \mathrm{~cm}$. Histologically they are characterized by a mixed population of cells, including, mucin-producing cells, epidermoid cells with squamoid differentiation, clear cells, and intermediate cells that may predominate in numbers and are believed to be the progenitor of the other types of cells. No myoepithelial cells are present [29].

The clinical behavior of MEC has proved to be difficult to predict but correlations to tumor grade and stage have been reported [30-33].The histologic features that are most useful in predicting the aggressive nature of these tumors are: 1) a minor cystic component (less than 20\%); 2) tumor necrosis; 3) neural invasion; 4) cellular anaplasia; and 5) brisk mitotic activity [29]. Based on the presence or absence of these features and the clinical behavior, MEC are classified as low, intermediate, and high grade.

Low-grade MEC are well circumscribed, with pushing margins and dilated cystic areas containing mucin. Mucinproducing, intermediate, or epidermoid cells make up the lining of these cystic structures. As the grade worsens, the tumors become more infiltrative, poorly circumscribed, cystic formations are lost, and nests of tumor become more solid and irregular with intermediate or epidermoid cells dominating [34].

High-grade MEC are characterized by the invasion of adjacent structures, atypical mitoses, necrosis, perineural 
invasion, lymph node ( $40 \%$ to $50 \%$ ), and distant metastases (33\%). These high-grade lesions are differentiated from primary of metastatic squamous cell carcinoma by the presence of intracellular mucin [24]. Sebaceous and clear cell carcinomas are additional differential diagnosis to consider.

Histologic grade and tumor stage appear to have profound effects on survival [11, 22]. Aro et al. [35] found a statistically significant difference in disease free survival (DFS) by grade between low-grade MEC and intermediate / high-grade $\operatorname{MEC}(P=0.001)$.

\subsection{Acinic Cell Carcinoma}

Acinic cell carcinoma (AcCC) is the second most common malignant tumor involving the parotid gland [14], representing $15 \%$ of malignant parotid gland neoplasms. It accounts for approximately $5 \%$ to $17 \%$ of all salivary gland tumors and $10 \%$ to $17 \%$ of all malignant salivary gland tumors [28, 36-38]. The parotid gland is composed almost exclusively of serous type acini, and it is the most common site of AcCC ( $80 \%$ to $90 \%$ of cases); other reported sites are the palate (up to $15 \%$ ), submandibular gland (4\%), and sublingual gland (1\%). AcCC occurs most often in the fifth decade of life and in women more often than in men (ratio $3: 2)[28,36]$. It is generally a low-grade carcinoma with indolent behavior. Recurrences are usually delayed, sometimes after decades. In a series reported by Ellis et al. [28], $12 \%$ of tumors recurred and $8 \%$ metastasized (bone, lung, and brain). The regional lymph nodes were the most common site of metastases. Spafford et al. [39] reported cervical lymphadenopathy to be present in $10 \%$ to $15 \%$ of cases of AcCC and Spiro et al. [40] in a series of 67 cases with AcCC treated before 1968, identified five cases $(7.5 \%)$ with cervical metastases at the time of initial treatment. It is interesting that this tumor is the most common bilateral malignant salivary gland neoplasm, although its bilateral presentation is not nearly as common as the bilateral presentations of benign tumors (Warthin's tumor and pleomorphic adenoma) [36].

AcCC are typically encased in a fibrous capsule, grossly resembling round circumscribed nodules with a tan surface. The cut surface is solid but may show cystic degeneration and hemorrhage. Histologically, there are five cell types [29]: 1) serous acinar cells (explaining the predilection for the parotid gland); 2) cells with clear cytoplasm; 3) intercalated ductal cell; 4) nonspecific glandular cell, and 5) vacuolated cell. The microscopic recognition of AcCC also requires a strong appreciation for its varied growth patterns. There are four histologic growth patterns: solid, microcystic, papillary, and follicular [13, 29, 41]. Caution must be taken not to misread the solid pattern as normal parotid parenchyma, the papillary-cystic pattern as cystic mucoepidermoid carcinoma, or the follicular pattern as metastatic thyroid carcinoma [29].

Serous acinar differentiation is developed most fully in the acinic cell. These cells have dark round nuclei and granular purplish cytoplasm. The diagnosis of AcCC may be difficult to establish, especially when some other cell type dominates the histopathology picture. Some examples of this are the predominance of clear cells might cause confusion with mucoepidermoid carcinoma, clear cell adenocarcinoma, and metastatic renal cell carcinoma. In these circumstances, the diagnostic acinic cells can be identified using a periodic acid-Schiff (PAS) reagent (their cytoplasmic secretory granules are PAS positive and diastase resistant) [29, 42]. Overall survival has been crudely estimated to be about $84 \%[28,38]$. Survival at 5 years has been reported between $76 \%$ [43] to $90 \%$ [44, 45], but fell to $56 \%$ at 20 years, emphasizing the need for longterm follow-up [28, 44].

\subsection{Adenoid Cystic Carcinoma}

Adenoid cystic carcinoma (ACC) accounts for approximately $10 \%$ of all salivary gland neoplasms. This is the most common malignant disorder to arise in the submandibular, the sublingual, and the minor salivary glands[14]. More than two thirds (65\%) of them arise from the minor salivary glands, most commonly located within the oral cavity (palate) followed by the nasal cavity and nasopharynx. They were considered the most common malignant salivary gland tumor to involve the palate, but they are now outnumbered at this site by polymorphous low-grade adenocarcinoma [28]. ACC arise more often in women than in men and tend to affect adults in their fifth through seventh decades of life, often presenting as an otherwise asymptomatic mass [29, 34].

Its natural history demonstrates a paradox. First, tumor growth is slow, but its clinical course is unyielding and progressive. Second, operative intervention is usually possible, but multiple local recurrences are the norm. Third, metastatic spread to regional lymph nodes is rare, but distant spread to the lungs and bones is common (40\% to $50 \%$ of the cases). And fourth, 5-year survival rates are expectantly high, but 10 to 20-year survival rates are dismally low [29]. Tumor stage is considered the most reliable indicator of overall outcome [46], but some authors have questioned the importance of histologic sub-typing. There is a strong positive correlation between site of origin and prognosis. The more favorable outcome with major (relative to minor) salivary gland ACC is attributed to the earlier discovery of the neoplasm at these more accessible locations [47].

ACC is not encapsulated or partially encapsulated and infiltrates the surrounding tissue (the risk of local failure is approximately 50\% with surgery alone) [16]. Histologically they have a basaloid epithelium clustered in nests in a hyaline stroma. ACC can be categorized into three growth patterns, cribriform, tubular, and solid patterns [48]. The most common histologic subtype is the cribriform type (44\%), characterized by a "Swiss cheese" pattern of vacuolated areas. The prognosis for the cribriform subtype is intermediate. The tubular subtype (35\%) carries the best prognosis and is characterized by cords and nests of malignant cells. The solid subtype $(21 \%)$ has the worst 
prognosis in terms of distant metastasis and long-term survival [49]. Solid sheets of adenoid malignant cells characterize this subtype.

A sole feature of ACC is the propensity for perineural invasion (50\% to $70 \%$ of the cases) [14], even with earlystage tumors. It can spread centripetally through the skull base and peripherally along both named and unnamed nerves. For this reason, adjuvant radiation that includes the anatomic course of the regional named nerves is often recommended. Lymphatic spread is uncommon, and consequently neck dissection or wide-field radiation to regional lymphatics is rarely recommended. Skip metastasis are known to occur despite clear surgical margins [50]. This malignancy is graded according to Szanto et al. [49], cribriform or tubular (grade I), less than $30 \%$ solid (grade II), or greater than $30 \%$ solid (grade III). In patients treated by similar modalities, the cribriform and tubular variants of ACC demonstrated no difference in the rate of distant metastases and overall survival. The cribriform variant demonstrated a significantly worse prognosis in terms of local recurrence rate (up to $47 \%$ ).

\subsection{Carcinoma Ex Pleomorphic Adenoma / Mixed Malignant Tumor}

Carcinoma ex pleomorphic adenoma (CXPA) also known as mixed malignant tumor is defined as a carcinoma arising de novo from a primary or recurrent benign pleomorphic adenoma (PA) [51, 52]. Microscopically, there may be one small malignant growth within a PA, or the malignant lesion with destructive infiltrative growth pattern may replace the benign tumor. Nouraei et al. [52] and Zbaren et al. [53] observed that $25 \%$ of their 28 patients and $21 \%$ of their 24 patients, respectively, had a previously treated PA.In a series of 60 cases, Gnepp[51] noted that CXPA constitutes approximately $3.6 \%$ of all salivary gland neoplasm's, $6.2 \%$ of all mixed tumors, and $11.6 \%$ of all malignant salivary gland neoplasm's. CXPA predominantly affects the major salivary glands with a majority of cases noted in the parotid and submandibular glands. The cancer has been known to manifest in the minor salivary glands in the oral cavity, particularly the hard and soft palate [54-56]. It has a prevalence rate of 5.6 cases per 100,000 malignant neoplasm's and a yearly incidence rate of 0.17 tumors per one million persons [51]. This malignancy is found predominantly in the sixth to eighth decades of life and is slightly more common in females [56].

CXPA should not be considered as a distinct neoplastic entity. More accurately, it should be considered as three very different tumor types (CXPA, metastasizing mixed tumor, and carcinosarcoma)[29]. CXPA represents a PA that has undergone malignant transformation, pathologic documentation of a former or coexisting PA is mandatory to establish the diagnosis [29]. The carcinomatous element is recognized by cytologic atypia and invasive tumor growth outside the tumor capsule [29]. In most cases the malignant component is an adenocarcinoma that cannot be specified further. In these circumstances, behavior is predicted by histologic grade [28]. The degree of infiltration also has a significant impact on prognosis. In one series [57], all patients died when their tumors extended more than eight millimeters beyond the tumor capsule, but none died with less significant invasion. In other instances the malignant component may take on the form of other well-recognized types of salivary gland malignancies (e.g., adenoid cystic carcinoma). In these cases, prognosis and treatment depend on the histologic type of the carcinoma [29].

Metastasizing mixed tumor represents an apparently harmless PA that has metastasized to regional lymph nodes or a distant site. This puzzling conduct cannot be predicted on the basis of any histologic features of the primary tumor. Both the primary tumor and metastasis are characterized by the absence of cytologic atypia [29]. Notwithstanding its harmless appearance, metastasizing mixed tumor has been associated with a mortality rate of $22 \%$ [58]. The time from initial treatment of the primary tumor to metastatic spread usually is long and interspersed by incidents of local tumor recurrence. Complete surgical removal of the primary tumor is probably the best way to prevent any future threat of spreading.

Carcinosarcoma is a rare and fatal neoplasm composed of both carcinomatous and sarcomatous elements. It is the only mixed tumor with a truly biphasic malignant nature [59]. The sarcomatous component usually takes the form of chondrosarcoma, but fibrosarcoma, osteosarcoma, and malignant fibrous histiocytomas also have been described.

Overall, the survival rate for CXPA is poorer than for most salivary gland malignancies and the survival rates differ from series to series. In older series, Gnepp[51] reported a 5 -year survival range of $25 \%$ to $65 \%$. Olsen et al. [60] noted a 5-year disease-specific survival rate of $37 \%$ in 73 patients with this tumor and Nouraei et al. [52] reported $44 \%$ survival rates in 28 patients with this cancer. On the other hand, Zbaren et al. [53] noted a higher survival rate of $75 \%$ in their series of 24 patients and Luers et al. [61] reported a survival rate of $60 \%$ in 22 patients with the malignancy. Loco-regional recurrence is considered to be a major prognostic factor for patients with CXPA. Olsen et al. [60] reported a local recurrence rate of $23 \%$ and regional recurrence in $18 \%$ of patients with CXPA.

\subsection{Other Types of Salivary Gland Malignancies}

\subsubsection{Adenocarcinomas}

These are a minority of malignant salivary gland tumors. These are adenocarcinomas lacking any characteristic feature that helps in classifying them as other specific types of epithelial tumors of salivary origin. Thus, it is a diagnosis of exclusion. They fall broadly into two categories: 1) the occasional low-grade terminal duct/polymorphous adenocarcinoma (PLGA) arising from the intercalated ducts, which microscopically resemble lobular carcinoma of the breast [62] and are most commonly found in the palate, and 2) the high-grade salivary duct adenocarcinoma that arise from the major salivary glands and typically metastasize early and 
demonstrate dismal prognosis [14].

Salivary duct adenocarcinoma is a term that was selected because of its resemblance to ductal carcinoma of the breast [72]. It is characterized by an aggressive behavior, early metastasis, local recurrence and significant mortality. Nearly $85 \%$ of the cases occur in the parotid gland followed by the submandibular gland [73]. Rarely is it observed in the hard palate. The tumor has a predilection for older men (male to female ratio 5.5 to 1 ) in the sixth to seventh decades of life $[74,75]$. Cervical lymphadenopathy is detected in approximately $35 \%$ of the cases [73]. The clinical course is rapid and the prognosis is dismal [76]. Local aggressiveness in the form of extra-salivary extension has been frequently noted.

Most squamous cell carcinomas (SCC) in the salivary glands represent spread from skin primaries and usually occur in the parotid gland. In patients with SCC of the skin, the overall risk of metastasis to regional lymph nodes is reported to be $1 \%$ to $5 \%[81,82]$. Metastatic cancer to the parotid gland accounts for less than $10 \%$ of all malignancies found in this gland. Of these metastases to the parotid lymph nodes, $40 \%$ are SCC [83].True SCC of the salivary gland is very rare, with a reported frequency of approximately $0.3 \%$ to $9.8 \%$ of all malignant parotid gland tumors $[84,85]$. Debate exists as to whether or not true primary SCC of the salivary glands exists.

\section{Immunohistochemistry}

Salivary gland malignancies show a wide range of forms and many of them share microscopic characteristics, a distinctive immunophenotype for a given salivary gland tumor would be of immense advantage, especially in situations were small biopsies are obtained. Numerous studies have been carried out that have mainly focused on the cytokeratins [87], S100 [88], actins [89], epithelial membrane antigen, vimentin [89], Ca-50 [90], and carcinoembryonic antigen [90]. Unfortunately, none of these markers has proved specific or consistent enough to be reliably used in a diagnostic context [1]. There is now some evidence to suggest that expression of the product of the c-kit proto-oncogene (CD117) [91-93] and glial fibrillary acidic protein (GFAP) $[88,94,95]$ might help in distinguishing between the three most common salivary gland tumors which also share morphological features, namely pleomorphic adenoma, polymorphous adenocarcinoma and adenoid cystic carcinoma.

\section{Diagnostic Evaluation and Staging}

One of the most important means to distinguish inflammatory from neoplastic lesions of the salivary glands is a well-performed history and physical examination [96, 97]. The typical presentation of a benign salivary gland tumor is a painless slow-growing mass on the face (parotid gland), angle of the jaw (parotid tail, submandibular gland), or neck (submandibular gland) or a swelling at the floor of the mouth (sublingual gland) [14]. When small, malignant tumors of the mayor salivary glands are indistinguishable clinically from benign tumors. An abrupt increase in size may be suggestive of degeneration into a malignant malignancy. Other hints of malignant degeneration include new onset of pain, facial nerve weakness, rapid growth, paresthesias, hoarseness, skin involvement, a fixed lesion, and cervical lymphadenopathy [98, 99]. Unrelenting facial pain is indicative of malignant degeneration because approximately $10 \%$ to $15 \%$ of malignant parotid neoplasm's present with pain $[11,98]$.

A space-occupying lesion in the parapharyngeal space needs to be differentiated from a benign or malignant neoplasm; usually malignant lesions invade the masseter and pterygoid musculature producing trismus. The clinical presentation of minor salivary gland tumors is more diverse due their wide spread distribution throughout the upper aerodigestive track (Table 2). Most often, these lesions present as a submucosal swelling, but they may be ulcerated when the overlying mucosa has been traumatized. As such, they may be clinically indistinguishable from a squamous cell carcinoma of the head and neck.

The three essential steps in the diagnosis of a parotid gland tumor are: 1) the differentiation of a parotid mass from a cervical mass, 2) differentiating a malignant lesion from an inflammatory lesion, and 3) discriminating the malignant tumors from the benign ones, because this will have effects on the operative approach [1].

Fine-needle aspiration (FNA) has gained wide acceptance as a first-line diagnostic procedure in the diagnosis of salivary gland lesions, with reported accuracy rates of $74 \%$ to $98 \%$ [100-108]. FNA is a quick, safe, relatively inexpensive, minimally invasive procedure that can be performed in any outpatient setting with virtually no complications [108]. While some advocate routine preoperative FNA because it can change the clinical approach in up to $35 \%$ of cases [14], others feel that it provides little to the management of small, obvious parotid gland tumors. In the literature false negative rates have ranged from $5 \%$ to $15 \%[28,106,108]$. This inconsistency in diagnostic exactitude can be ascribed to many factors, including the experience of the cytopathologist and the quality of FNA material [108]. Another shortcoming of FNA is a small rate of non-diagnostic (inadequate) specimens, although ultrasonographic or CT guidance can reduce this problem [109]. It has been shown that with salivary gland FNA, there is basically no tumor seeding along the needle tract with only a few case reports reporting on this extremely rare situation [110-112]. The sensitivity and specificity of FNA for the diagnosis of salivary gland neoplasm's varies significantly in the many reported series, ranging from $58 \%$ to $90 \%$ and $71 \%$ to $100 \%$ respectively [100, 101, 106, 108, 109, 113-116] (Table 3).

Frozen Section: The use of frozen section is 
controversial because diagnosis depends on the experience of the pathologist with regard to salivary gland malignancies. The false-positive rate reported in the literature ranges from $0 \%$ to $12.5 \%$ (Table 4) [119-123]. Seethala et al. [70] have quoted three indications for the use of frozen section analysis during operative removal of a salivary gland tumor. First, frozen section analysis is useful in determining the extent of tumor spread. Frozen section analysis can provide quick answers to crucial intraoperative questions such as the presence of local extension into the facial nerve or metastatic spread to regional lymph nodes. Second, frozen section analysis is helpful in clarifying the status of the surgical margins. Third, frozen section analysis remains useful as a diagnostic tool when the preoperative FNA findings are non-diagnostic or when the FNA diagnosis is at odds with the clinical and/or intraoperative findings.

The staging system for salivary gland malignancies is based on an extensive retrospective review of the world literature [124]. Several factors affect patient survival, including the histologic diagnosis, cellular differentiation of the tumor (grade), site of origin, size, degree of fixation or local extension, facial nerve involvement, and the status of regional lymph nodes as well as distant metastases. The classification involves the four prevailing clinical variables: tumor size, local extension of the tumor, nodal metastasis, and distant metastasis. The T4 category is divided into T4a and $\mathrm{T} 4 \mathrm{~b} . \mathrm{T} 4 \mathrm{a}$ indicates moderately advanced lesions and $\mathrm{T} 4 \mathrm{~b}$ reflects very advanced lesions with local extension. Histologic grade, patient age, and tumor site are important additional factors that should be recorded for future analysis and potential inclusion in the staging system (Table 5 and 6). There is no commonly accepted staging system for tumors of minor salivary gland origin but often in the literature such tumors are staged according to the AJCC system appropriate for the more common squamous cell carcinomas arising from the same location [14]

Histologic grading is applicable only to some types of salivary gland cancers: mucoepidermoid carcinoma, adenocarcinoma not otherwise specified, or when either of these subtypes is found in the carcinomatous element of the carcinoma in pleomorphic adenoma. In most instances, the histologic type defines the grade (i.e., salivary duct carcinoma is high grade; basal cell adenocarcinoma is low grade) [124].

Presently there are no imaging modalities that can help differentiate benign from malignant salivary gland tumors. Ultrasonography (US) cannot distinguish between them but can help localize them and its most important role is to guide the FNA aspirate or biopsy [125]. Corr et al. [126] compared US and contrast-enhanced computed tomography (CT) modalities in 40 patients and found the sensitivity of US and CT in detecting parotid lesions to be $100 \%$ and $97.5 \%$, respectively. CT scans provide a superb way to appraise not only the parotid tumor but also the regional lymphatic's (enlarged nodes that might not be clinically palpable), and cortical bony involvement [14]. CT has high sensitivity $(90 \%)$, but it has relatively low specificity (around 60\%), with respect to its ability to distinguish between benign and malignant tumors of the salivary gland [128]. Magnetic resonance imaging (MRI) provides better soft tissue detail that CT and can help evaluate the relationship of the tumors with vascular structures. MRI findings of salivary gland tumors have been depicted in a number of reports [129-131]. It has been stated that the findings of low signal intensity and irregular tumor margins on T2-weighted MRI images indicate malignancy [129, 130]. Nevertheless, the reported sensitivities and specificities of these findings have been low and significantly overlapping $[131,132]$. MRI is better to CT in terms of sensitivity (nearly $100 \%$ ) and specificity (80\%), in distinguishing benign from malignant tumors [133]. 18FFDG PET/CT (PET/CT) has been reported to be more accurate than $\mathrm{CT}$ or MRI for the detection of malignant tumors, whereas the glucose uptake levels show a good correlation with the histologic grading for head and neck cancer [134]. PET/CT shows low accuracy for discriminating between benign and malignant tumors, as benign tumors such as pleomorphic adenoma and Warthin's tumors also have high glucose uptake values [135, 136]. $\mathrm{PET} / \mathrm{CT}$ provides more precise diagnostic information for the assessment of high-grade salivary gland malignancies than does $\mathrm{CT}$ and it has a major impact on making treatment decisions for patients with a high-grade salivary malignancy.

\section{Management of Salivary Gland Malignancies}

\subsection{Operative Management}

An operation with the complete removal of the tumor, including a cuff of histologically normal tissue for adequate margins, is the mainstay of treatment for both major and minor salivary gland malignancies. The minimum treatment for low-grade malignancies of the superficial portion of the parotid glands that are not fixed or involve the facial nerve $(\mathrm{FN})$ is a superficial parotidectomy with dissection and preservation of the FN. In carefully selected patient with small lesions arising in the tail of the parotid gland, a more limited local resection without formal FN dissection may be feasible if negative margins are obtained. For all other lesions, a total parotidectomy is often indicated. The facial nerve or its branches should be resected if involved by tumor only; repair can be done concurrently [13, 14, 137]. Where possible, nerve grafting is the preferred method of FN reconstruction. Although elderly patients with parotid malignancy have traditionally been considered poor candidates for nerve grafting, good results have been demonstrated within nine months of FN repair [138]. These patients usually will show improvement in muscle tone. Gold weight eyelid implants and fascial slings can be used when nerve grafting is not possible, or is unsuccessful. Piecemeal excision of a malignant parotid neoplasm in 
order to spare the FN or its branches violates basic oncologic principles and should be condemned. Twentynine to forty percent of patients with malignant parotid gland tumors will require FN sacrifice in order to remove the disease. One of the chief factors in intraoperative decision-making is the relationship of the tumor to the nerve, whether the mass lies above or below the plane of the nerve. The FN branches should not be sacrificed unless the tumor is adherent to or surrounds the nerve. It is crucial to avoid enucleation because it greatly increases the likelihood of recurrence (up to $80 \%$ ) and nerve damage. When a tumor is found to be deep to the FN (deep lobe or endofacial portion of the gland) several surgical options are available. For lesions that are small and do not have significant parapharyngeal extension, the FN is initially exposed by a superficial parotidectomy and then the branches can be displaced to allow for tumor removal. When parapharyngeal extension is present, the submandibular gland can be removed to facilitate transcervical access or a paramedianmandibulotomy can be performed when confronted with large lesions.

For small lesions a formal level $\mathrm{Ib}$ dissection is preferred over a simple gland excision in malignant salivary gland tumors of the submandibular and sublingual glands. If the tumor extends to or through the gland capsule involving adjacent structures the resection may have to involve the bed of the gland (digastric, mylohoid, and hyoglossal muscles), adjacent nerves (lingual, hypoglossal, and marginal mandibular branch of the FN), the mandible or the floor of the mouth, and/or sublingual glands. Patients with high grade tumors may require a composite resection. As with the FN in parotidectomy, the lingual, hypoglossal, and marginal mandibular nerves are preserved unless there is evidence either preoperatively or intraoperatively of their direct involvement by the tumor [13]. The surgical approach for tumors arising in minor salivary glands will depend on the site of origin, but is generally similar to that utilized for squamous cell carcinoma arising at the same site. Lesions arising in the larynx may be amenable to either conservation laryngeal surgery or total laryngectomy. Lesions arising from the base of the tongue can be approached through a paramedianmandibulotomy. Hard palate tumors may require a transoral partial maxillectomy.

The FN is one of the most critical structures encountered during surgical extirpation of the parotid gland especially since these closely approximate the nerve [139]. Table 7 shows the incidence rates reported in the literature for FN paralysis (transient or permanent).

There are two different ways to identify the FN intraoperatively, the antegrade or retrograde methods. The antegrade dissection uses several operative landmarks that have been described to help identify the FN during parotid gland operations: 1) posterior belly of digastric muscle at its attachment to the digastric groove (nerve just superior and on the same plane as the muscle attachment) [144], 2) the mastoid process and external auditory meatus where the $\mathrm{V}$-shaped tympanomastoid suture line is located (nerve approximately 6 to $8 \mathrm{~mm}$ medial to the suture line) [145147], the tragal pointer which forms part of the tragal cartilage (nerve approximately $1 \mathrm{~cm}$ medial and anteroinferior to tip of the pointer) $[145,146,148]$ and the styloid process $[145,146]$. The retrograde dissection may be employed to trace one of the terminal branches proximally if the tumor obscures the main FN trunk [14]. The landmarks employed for retrograde dissection are: 1) buccal branch (runs with the parotid duct either superiorly or inferiorly); 2) temporal branch (crosses the zygomatic arch parallel with the superficial temporal artery and vein); 3) marginal mandibular branch (runs along the inferior border of the parotid superficial to the RMV).

The rate of cervical lymph node metastasis in patients with salivary gland malignancies is quit low with approximately $16 \%$ of parotid carcinomas and $8 \%$ of submandibular / sublingual malignancies presenting with lymphadenopathy. Tumor histology relates directly with the incidence of positive lymph nodes and also significantly impacts overall survival (OS). Positive cervical lymphadenopathy decreases OS in patients with mayor salivary gland malignancies by more than $50 \%$. The management of the neck in a patient with positive nodes is a modified radical neck dissection with resection of the primary lesion. The management of the N0 neck is based on the tumors characteristics [96, 97]. High-grade tumors, advanced $\mathrm{T}$ stage, presence of FN paralysis preoperatively, and histologic demonstration of extra-glandular spread or peri-lymphatic invasion merit an elective neck dissection [96]. An elective neck dissection should include level IIb when dealing with parotid malignancies because of the high rate of involvement [149]. In addition, a very high rate of metastasis has been noted with nasopharyngeal minor salivary gland malignancies, meriting planned neck dissection at the time of surgical intervention [150].

\subsection{Radiation Therapy}

Salivary gland malignancies are very radiosensitive tumors; postoperative irradiation is well established as part of the adjuvant treatment in patients at high risk of loco regional recurrence [151-153]. Numerous studies have shown that loco regional control rates are enhanced by the addition of postoperative radiotherapy (Table 8). Armstrong et al. [152], in a matched pair analysis of 46 patients with major salivary gland malignancies, showed an improvement in loco regional control and OS with adjuvant radiotherapy in patients with advanced disease and nodal involvement. Garden et al. [154], described loco regional control rates in 166 malignant parotid gland tumors managed with adjuvant radiotherapy. Twenty-nine percent of patients had disease recurrence, of which $9 \%$ were local and $6 \%$ were regional (neck) failures. Patients with positive margins and named nerve involvement had poor local control, despite adjuvant radiotherapy. Guillamondeguiet al. [156] reported a local control rate of $66 \%$ for surgery alone and $86 \%$ for surgery and postoperative radiotherapy.

Postoperative adjuvant radiotherapy is recommended for 
high-grade tumors, advanced stage (T3/T4) tumors, close $(</=5 \mathrm{~mm})$ or positive surgical margins, certain histologic types such as ACC, perineural or lymphatic invasion, extension of tumor beyond the gland, regional nodal metastasis, and recurrent disease because of the associated high loco regional failure rates between $30 \%$ to $60 \%$ after surgery alone [152, 157-159]. The radiation treatment portals include the preoperative extent of the gland with 2 $\mathrm{cm}$ margin. Elective ipsilateral neck irradiation is indicated for high-grade and T3/T4 tumors [97]. Postoperative radiation therapy to the neck is indicated for solitary metastatic nodes larger than $2 \mathrm{~cm}$, multiple metastatic nodes, and extra capsular extension [151]. Patients with clinically positive lymphadenopathy at presentation were found to have three or more positive lymph nodes in $60 \%$ of the cases, in a study with levels IV and $\mathrm{V}$ being involved in approximately $50 \%$ of the patients [157]. Recurrences in the contralateral untreated neck are infrequent [97, 151]. However, for minor salivary gland tumors arising in the midline both side of the neck are at risk.

Unlike the more common head and neck squamous cell carcinomas (HNSCC), the time factor seems to play a less important role in combined modality treatments of salivary gland tumors. Salivary gland malignancies have a very slow growth rate hence a delay in the start of postoperative radiation therapy should not be that deleterious. In a retrospective series Terhaard et al. [157] should no adverse effect of delaying the radiation treatment until after 12 weeks after the operation.

Various beam compositions, electrons, or mixed electron photon beams are used to reduce the radiation toxicity to surrounding normal tissue and the contralateral salivary glands. For parotid gland tumors, the superior margin is generally above the zygomatic arch, inferior margin is at the inferior neck field, the posterior margin is at the mastoid process, and the anterior margin is beyond the second upper molar to include Stensen's duct [97]. When a named nerve is involved, the neural pathway up to the skull base is included in the treatment volume. The skull base does not need to be covered for focal microscopic perineural invasion [160].In a retrospective series of 50 patients with submandibular ACC, Storey et al. [161] described covering the neural pathways to their respective foramina in the base of the skull when a named nerve was involved in $94 \%$ of their patients. The doses to the skull base ranged from 45 to $60 \mathrm{~Gy}$, and no recurrences at the skull base were noted. They reported a loco regional control rate for these high-risk tumors treated with an operation and postoperative radiotherapy of $88 \%$ at 10 years.

The radiation treatment is usually given in the form of megavoltage photons and electrons [154]. The radiation dose to the surgical site and involved dissected neck is 60 Gy, dissected uninvolved nodal sites are treated to $56 \mathrm{~Gy}$, and undissected elective sites are treated to $50 \mathrm{~Gy}$ in $2 \mathrm{~Gy}$ daily fractions. Postoperative radiation therapy should begin at approximately 3 to 4 weeks after surgery. Garden et al. [154] reported a trend for patients with positive margins or named nerve involvement to have improved local control if they received doses greater than $60 \mathrm{~Gy}$.

The applicability of neutron beam irradiation as a standard for all salivary gland malignancies is questionable because of its increase toxicity, lack of improved OS compared to photons, and limited number of facilities providing neutron beam therapy. Compared to photons, neutrons are characterized by a reduced oxygen enhancement ratio, minimal sub-lethal and lethal damage repair of the cells between fractions of radiation, and less variation of sensitivity through the cell cycle [97]. The Radiation Therapy Oncology Group and MRC72A [162] is a phase III randomized clinical trial comparing neutrons and photons for the treatment of inoperable primary or recurrent salivary gland malignancies. The 10-year followup report showed that on actuarial basis, there was a statistically significant improvement in local control $(56 \%$ vs. $17 \%, \mathrm{P}=0.009$ ) favoring neutrons. The overall survival rate was not statistically different $(25 \%$ vs. $15 \%)$. Severe treatment-related toxicities were higher in the neutron arm.

\subsection{Chemotherapy Therapy}

Combining radiation therapy with surgery has resulted in improved local and regional control of the disease, but has not always translated to improve OS, because of metastatic disease, which suggests the need for effective systemic therapy. At this time systemic chemotherapy has a limited palliative role in the treatment of recurrent, advanced unresectable and metastatic malignant salivary gland tumors [164]. Due to the rarity of these tumors, good randomized control trials are not available to help with the management. Malignant salivary gland tumors are considered resistant to chemotherapy, but up to $50 \%$ of chemotherapy-naïve patients will experience a substantial response (tumor shrinkage) after combination chemotherapy, and rarely patients may experience a complete response. The majority of the responders and some of the patients who fail to show reduction in tumor size will have at least partial relief of tumor-related symptoms, such as pain (these responses are typically short-lived). There is little evidence that chemotherapy increases survival, though responders tend to live longer than non-responders [97]. Chemotherapy should be instituted for the management of symptomatic patients and asymptomatic patients with metastatic disease (ACC metastatic to the lung without symptoms) should not be offered chemotherapy. There is no evidence to validate the use of chemotherapy in the postoperative adjuvant setting.

The most active single agents include cisplatin [165], epirubicin[166], doxorubicin and 5-fluorouracil. The selection of chemotherapy agents is also challenging. A randomized control trial [167], comparing single-agent vinorelbine to the combination of vinorelbine plus cisplatin in patients with various histologic subtypes of malignant salivary gland tumors showed that the combination regimen was more active, with a $44 \%$ overall response rate versus 
$20 \%$ for the single agent. Trastuzumab has been studied in the management of salivary gland malignancies with limited responses due to the fact that most of the tumors did not overexpress HER-2/neu[168]. Other agents such as paclitaxel and carboplatin, an active combinationfor HNSCC, have been used with marginal success [169].

\section{Conclusions}

Treatment of malignant salivary gland tumors requires a thorough understanding of the anatomy and pathologic processes affecting these glands. FNA should be considered as part of the diagnostic evaluation but due to its varying sensitivities and specificities imaging modalities such as ultrasound, CT scans, and MRI should also be used as diagnostic adjuncts. Surgical extirpation is the primary modality for management of these tumors, nontraditional surgical approaches and instrumentation, as well as facial nerve monitoring, can be selectively utilized to try and decrease the morbidity associated with these surgical procedures. Certain malignant salivary gland tumors will warrant cervical lymphadenectomy. Adjuvant treatment is primarily achieved with radiation therapy. Chemotherapy continues to have a palliative role in the management of salivary gland tumors; however, research in this field is trying to identify a therapeutic role for chemotherapy in order to improve OS.

Table 1: WHO Histologic Classification

\begin{tabular}{ll}
\hline Low Grade Salivary Gland Tumors & High Grade Salivary Gland Tumors \\
\hline Acinic cell carcinomas & High-grade mucoepidermoid carcinomas \\
Low-grade mucoepidermoid carcinoma & Adenoid cystic carcinomas \\
Oncocytic carcinoma & Most adenocarcinomas (salivary duct carcinoma) \\
Myoepithelial carcinoma & Malignant mixed tumors (carcinoma ex-pleomorphic adenoma) \\
Papillary cystadenocarcinoma & Undifferentiated carcinoma \\
Low-grade adenocarcinoma (polymorphous, basal cell, and terminal duct) & \\
\hline
\end{tabular}

Table 2: Clinical Presentation of Minor Salivary Gland Tumors

\begin{tabular}{llll}
\hline$[1]$ & Location & {$[2]$} & Clinical Presentation \\
\hline$[3]$ & Nasal septum and sinuses & {$[4]$} & Hemorrhage and upper airway compromise \\
{$[5]$} & Base of the tongue & {$[6]$} & Dysphagia and globus sensation \\
{$[7]$} & Laryngeal lesions & {$[8]$} & Hoarseness \\
\hline
\end{tabular}

Table 3: Sensitivity and Specificity of Fine-Needle Aspiration for the Diagnosis Salivary Gland Neoplasms

\begin{tabular}{lllll}
\hline Study & Year & Patients (n) & Sensitivity (\%) & Specificity (\%) \\
\hline Carjulis et al. [170] & 1997 & 151 & $91 \%$ & $96 \%$ \\
Al-Khajaji et al. [171] & 1998 & 154 & $82 \%$ & $86 \%$ \\
Stewart et al. [106] & 2000 & 341 & $92 \%$ & $100 \%$ \\
Cohen et al. [102] & 2004 & 258 & $82 \%$ & $85 \%$ \\
Riley et al. [114] & 2005 & 100 & $85 \%$ & $97 \%$ \\
Seethala et al. [108] & 2005 & 220 & $86 \%$ & $92 \%$ \\
Carillo et al. [115] & 2009 & 135 & $92 \%$ & $95 \%$ \\
Brennan et al. [113] & 2010 & 103 & $70 \%$ & $94 \%$ \\
Cho et al. [109] & 2011 & 244 & $76 \%$ & $100 \%$ \\
Kechagias et al. [101] & 2011 & 107 & $90 \%$ & $98 \%$ \\
\hline
\end{tabular}

Table 4: False Positive Rates of Frozen Sections During Salivary Gland Operations

\begin{tabular}{cccc}
\hline Author & Year of Study & Frozen Sections (n) & \multicolumn{2}{c}{ False Positive Rate } \\
\hline Tan [172] & 2006 & 91 & $0 \%$ \\
Wong [119] & 2002 & 32 & $12.5 \%$ \\
Iwai [120] & 1999 & 147 & $0.7 \%$ \\
Carvalho[121] & 1999 & 146 & $2.0 \%$ \\
Zheng[122] & 1997 & 65 & $6.9 \%$ \\
Tew[173] & 1997 & 144 & $4.0 \%$ \\
Megerian[105] & 1994 & 247 & $8.8 \%$ \\
\hline
\end{tabular}


Table 5: AJCC Staging System for Salivary Gland Malignancies [124]

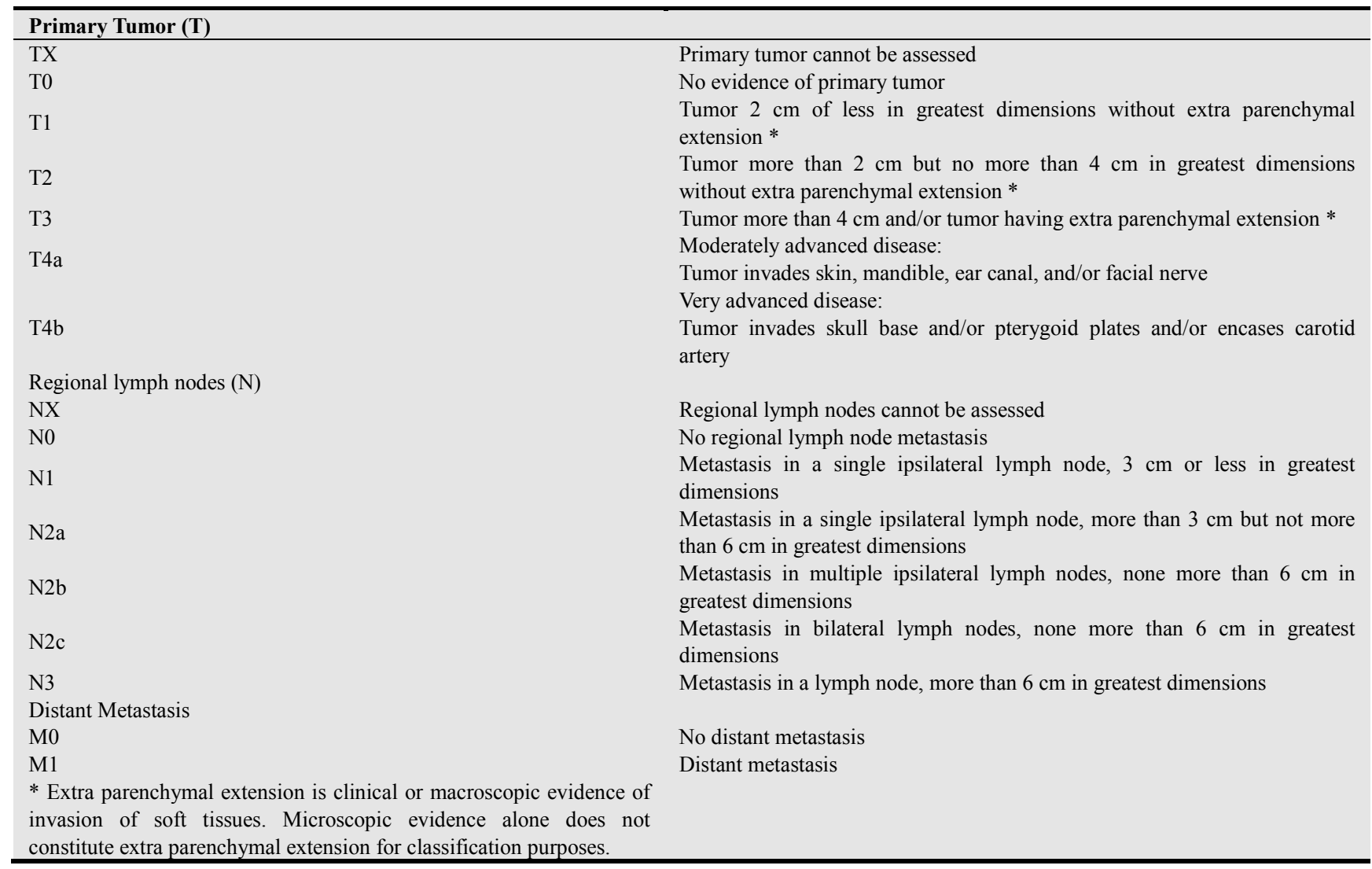

Table 6: Anatomic Stage [124]

\begin{tabular}{|c|c|c|c|}
\hline Stage I & T1 & No & Mo \\
\hline Stage II & $\mathrm{T} 2$ & N0 & M0 \\
\hline \multirow[t]{4}{*}{ Stage III } & T3 & No & M0 \\
\hline & $\mathrm{T} 1$ & N1 & M0 \\
\hline & $\mathrm{T} 2$ & N1 & M0 \\
\hline & $\mathrm{T} 3$ & N1 & M0 \\
\hline \multirow[t]{6}{*}{ Stage IV A } & $\mathrm{T} 4 \mathrm{a}$ & No & M0 \\
\hline & $\mathrm{T} 4 \mathrm{a}$ & N1 & M0 \\
\hline & $\mathrm{T} 1$ & $\mathrm{~N} 2$ & M0 \\
\hline & $\mathrm{T} 2$ & $\mathrm{~N} 2$ & M0 \\
\hline & $\mathrm{T} 3$ & N2 & M0 \\
\hline & $\mathrm{T} 4 \mathrm{a}$ & $\mathrm{N} 2$ & M0 \\
\hline \multirow[t]{2}{*}{ Stage IV B } & $\mathrm{T} 4 \mathrm{~b}$ & Any N & M0 \\
\hline & Any T & N3 & M0 \\
\hline Stage IV C & Any T & Any N & M0 \\
\hline
\end{tabular}

Table 7: Incidence Rates in the Literature for Facial Nerve Injury

\begin{tabular}{|c|c|c|c|c|}
\hline Author & Patients (n) & Injured FN & Year & Percentage \\
\hline Umapathy et al. [174] & 154 & 25 (transient) & 2003 & $14 \%$ (transient) \\
\hline Bova et al. [175] & 170 & 39 (transient) & 2004 & $23.5 \%$ (transient) \\
\hline Gaillard et al. [176] & 131 & $56($ transient $)$ & 2005 & $42 \%$ (transient) \\
\hline Enget al. [177] & 159 & $\begin{array}{l}52 \text { (transient) } \\
2 \text { (permanent) }\end{array}$ & 2007 & $\begin{array}{c}55.9 \% \text { (transient) } \\
2 \% \text { (permanent) }\end{array}$ \\
\hline Roh et al. [178] & 123 & $\begin{array}{l}43 \text { (transient) } \\
1 \text { (permanent) }\end{array}$ & 2008 & $\begin{array}{c}34 \% \text { (transient) } \\
0.8 \% \text { (permanent) }\end{array}$ \\
\hline Lintworth et al. [179] & 934 & $\begin{array}{l}23 \text { (transient) } \\
8 \text { (permanent) }\end{array}$ & 2010 & $\begin{array}{c}6 \% \text { (transient) } \\
2 \% \text { (permanent) }\end{array}$ \\
\hline Mahmood et al. [180] & 64 & 6 (transient) & 2010 & $9 \%$ (transient) \\
\hline
\end{tabular}


Table 8: Local Regional Control Surgery versus Surgery Followed by Radiotherapy

\begin{tabular}{|c|c|c|c|c|}
\hline Author & Year & Patients (n) & Surgery & Surgery + PO Rx \\
\hline Fu et al [155] & 1977 & 100 & $46 \%$ & $86 \%$ \\
\hline Fitzpatrick [181] & 1986 & 403 & $27 \%$ & $73 \%$ \\
\hline Tran et al [182] & 1986 & 133 & $53 \%$ & $75 \%$ \\
\hline Armstrong et al [152] & 1990 & 46 & $66 \%$ & $73 \%$ \\
\hline Frankenthaler et al [183] & 1991 & 178 & $80 \%$ & $88 \%$ \\
\hline Mendenhall et al [158] & 2005 & 224 & & $89 \%$ \\
\hline Pohar et al [185] & 2005 & 163 & $63 \%$ & $89 \%$ \\
\hline Chen et al [186] & 2006 & 140 & $80 \%$ & $92 \%$ \\
\hline
\end{tabular}

\section{Abbreviations}

AcCC: Acinic cell carcinoma

ACC: Adenoid cystic carcinoma

CXPA: Carcinoma ex pleomorphic adenoma

Facial Nerve: FN

HNSCC: Head and neck squamous cell carcinoma

Mucoepidermoid carcinoma: MEC

Overall survival: OS

PLGA: Polymorphous low-grade adenocarcinoma

\section{Competing Interests}

The author(s) declare that they have no competing interests.

The authors have no non-financial competing interests (political, personal, religious, ideological, academic, intellectual, commercial or any other) to declare in relation to this manuscript.

\section{Authors Contributions}

Idea, literature review, manuscript elaboration, and editing: Rodrigo Arrangoiz and PavlosPapavasiliou.

Manuscript elaboration: David Sarcu.

Review and editing of manuscript: Thomas J. Galloway, John A. Ridge, and Miriam Lango.

\section{Authors Information}

Rodrigo Arrangoiz MS, MD Surgical Oncology Fellow at Temple / Fox Chase Cancer Center. Philadelphia.

PavlosPapavasiliuo MD Surgical Oncology Fellow at Temple / Fox Chase Cancer Center. Philadelphia.

David Sarcu MD. ENT Resident at Temple University.

Thomas J. Galloway MD Assistant Professor Radiation Oncology Department Temple / Fox Chase Cancer Center.

John A. Ridge MD, PhD. Chief of the Head and Neck Surgical Oncology Department, Professor at Temple / Fox Chase Cancer Center.

Miriam Lango MD Associate Professor Head and Neck Surgical Oncology Department at Temple / Fox Chase Cancer Center.

\section{References}

[1] Speight, P.M. and A.W. Barrett, Salivary gland tumours. Oral diseases, 2002. 8(5): p. 229-40.

[2] van der Laan, B.F., et al., Radiation-induced tumours of the head and neck. The Journal of laryngology and otology, 1995. 109(4): p. 346-9.

[3] Scanlon, E.F. and S.F. Sener, Head and neck neoplasia following irradiation for benign conditions. Comprehensive therapy, 1981. 7(12): p. 59-64.

[4] Belsky, J.L., et al., Salivary gland neoplasms following atomic radiation: additional cases and reanalysis of combined data in a fixed population, 1957-1970. Cancer, 1975. 35(2): p. 555-9.

[5] Horn-Ross, P.L., B.M. Ljung, and M. Morrow, Environmental factors and the risk of salivary gland cancer. Epidemiology, 1997. 8(4): p. 414-9.

[6] Spitz, M.R., et al., Risk factors for major salivary gland carcinoma. A case-comparison study. Cancer, 1984. 54(9): p. 1854-9.

[7] Muscat, J.E. and E.L. Wynder, A case/control study of risk factors for major salivary gland cancer. Otolaryngology-head and neck surgery : official journal of American Academy of Otolaryngology-Head and Neck Surgery, 1998. 118(2): p. $195-8$

[8] Saku, T., et al., Salivary gland tumors among atomic bomb survivors, 1950-1987. Cancer, 1997. 79(8): p. 1465-75.

[9] Leclerc, A., et al., Sinonasal cancer and wood dust exposure: results from a case-control study. American journal of epidemiology, 1994. 140(4): p. 340-9.

[10] Bonneterre, V., et al., Sino-nasal cancer and exposure to leather dust. Occupational medicine, 2007. 57(6): p. 438-43.

[11] Spiro, R.H., Salivary neoplasms: overview of a 35-year experience with 2,807 patients. Head \& neck surgery, 1986. 8(3): p. $177-84$

[12] Wahlberg, P., et al., Carcinoma of the parotid and submandibular glands--a study of survival in 2465 patients. Oral oncology, 2002. 38(7): p. 706-13.

[13] Lalwani, A.K., Current Diangosis and Treatment in Otolaryngology Head and Neck Surgery, ed. M. Anil K. Lalwani2008: The McGraw-Hill Companies. 
[14] Harrison, L.B., Head and Neck Cancer A multidisciplinary Approach. Third ed, ed. H. Louis B, Roy B. Sessions, Waun Ki Hong. Vol. 1. 2009, Philadelphia: Lippincott Wialliams and Wilkings. 1002.

[15] Theriault, C. and P.J. Fitzpatrick, Malignant parotid tumors. Prognostic factors and optimum treatment. American journal of clinical oncology, 1986. 9(6): p. 510-6.

[16] Oncology, N.C.C.N.C.P.G.i. Head and Neck Cancer. 2011 [cited 2011 2011]; Version2.2011:[

[17] Brandwein, M.S., et al., Diagnosis and classification of salivary neoplasms: pathologic challenges and relevance to clinical outcomes. Acta oto-laryngologica, 2002. 122(7): p. 758-64.

[18] Barnes, L., Everson, JW, Reichart, P, et al., World Health Organization classification of tumours: pathology and genetics of the head and neck. IARC Press, 2005.

[19] Rapidis, A.D., et al., Mucoepidermoid carcinoma of the salivary glands. Review of the literature and clinicopathological analysis of 18 patients. Oral oncology, 2007. 43(2): p. 130-6.

[20] Seifert, G., Sobin,l.h., Histological typing of salivary gland tumours. WHO international histological classification of tumour, 1991: Berlin, New York, Heidelberg.

[21] Batsakis, J.G., et al., Histogenesis of salivary gland neoplasms: a postulate with prognostic implications. The Journal of laryngology and otology, 1989. 103(10): p. 93944.

[22] Guzzo, M., et al., Mucoepidermoid carcinoma of the salivary glands: clinicopathologic review of 108 patients treated at the National Cancer Institute of Milan. Annals of surgical oncology, 2002. 9(7): p. 688-95.

[23] Goode, R.K., P.L. Auclair, and G.L. Ellis, Mucoepidermoid carcinoma of the major salivary glands: clinical and histopathologic analysis of 234 cases with evaluation of grading criteria. Cancer, 1998. 82(7): p. 1217-24.

[24] Brandwein, M.S., et al., Mucoepidermoid carcinoma: a clinicopathologic study of 80 patients with special reference to histological grading. The American journal of surgical pathology, 2001. 25(7): p. 835-45.

[25] Evans, H.L., Mucoepidermoid carcinoma of salivary glands: a study of 69 cases with special attention to histologic grading. American journal of clinical pathology, 1984. 81(6): p. 696-701.

[26] Eveson, J.W. and R.A. Cawson, Salivary gland tumours. A review of 2410 cases with particular reference to histological types, site, age and sex distribution. The Journal of pathology, 1985. 146(1): p. 51-8.

[27] Goode, R., El-Naggar, AK., Mucoepidermoid carcinoma. Wolrd Health Organization classification of tumour. Pathology and genetics of head and neck tumours, ed. E. In BarnesL, JW, Reichart P, Sidransky D.2005: Lyon.

[28] Ellis, G., Auclair, PL, Atlas of Tumor Pathology, Tumors of the Salivary Glands, series 3, fascicle 7, A.F.I.o. Pathology, Editor 1996: Washington DC. p. 353-355.
[29] Westra, W.H., The surgical pathology of salivary gland neoplasms. Otolaryngologic clinics of North America, 1999. 32(5): p. 919-43.

[30] Spiro, R.H., et al., Mucoepidermoid carcinoma of salivary gland origin. A clinicopathologic study of 367 cases. American journal of surgery, 1978. 136(4): p. 461-8.

[31] Healey, W.V., K.H. Perzin, and L. Smith, Mucoepidermoid carcinoma of salivary gland origin. Classification, clinicalpathologic correlation, and results of treatment. Cancer, 1970. 26(2): p. 368-88.

[32] Hamper, K., et al., Mucoepidermoid tumors of the salivary glands. Correlation of cytophotometrical data and prognosis. Cancer, 1989. 63(4): p. 708-17.

[33] Clode, A.L., et al., Mucoepidermoid carcinoma of the salivary glands: a reappraisal of the influence of tumor differentiation on prognosis. Journal of surgical oncology, 1991. 46(2): p. 100-6.

[34] Waldron, C.A., S.K. el-Mofty, and D.R. Gnepp, Tumors of the intraoral minor salivary glands: a demographic and histologic study of 426 cases. Oral surgery, oral medicine, and oral pathology, 1988. 66(3): p. 323-33.

[35] Aro, K., I. Leivo, and A.A. Makitie, Management and outcome of patients with mucoepidermoid carcinoma of major salivary gland origin: a single institution's 30-year experience. The Laryngoscope, 2008. 118(2): p. 258-62.

[36] Thompson, L.D., Salivary gland acinic cell carcinoma. Ear, nose, \& throat journal, 2010. 89(11): p. 530-2.

[37] Al-Zaher, N., et al., Acinic cell carcinoma of the salivary glands: a literature review. Hematology/oncology and stem cell therapy, 2009. 2(1): p. 259-64.

[38] Hoffman, H.T., et al., National Cancer Data Base report on cancer of the head and neck: acinic cell carcinoma. Head \& neck, 1999. 21(4): p. 297-309.

[39] Spafford, P.D., D.R. Mintz, and J. Hay, Acinic cell carcinoma of the parotid gland: review and management. The Journal of otolaryngology, 1991. 20(4): p. 262-6.

[40] Spiro, R.H., A.G. Huvos, and E.W. Strong, Acinic cell carcinoma of salivary origin. A clinicopathologic study of 67 cases. Cancer, 1978. 41(3): p. 924-35.

[41] Simpson, R.H., Classification of salivary gland tumours--a brief histopathological review. Histology and histopathology, 1995. 10(3): p. 737-46.

[42] Slater, L.J., Acinic cell carcinoma and PAS-positive granules. Oral surgery, oral medicine, oral pathology, oral radiology, and endodontics, 1998. 86(5): p. 507-8.

[43] Perzin, K.H. and V.A. LiVolsi, Acinic cell carcinomas arising in salivary glands: a clinicopathologic study. Cancer, 1979. 44(4): p. 1434-57.

[44] Lewis, J.E., K.D. Olsen, and L.H. Weiland, Acinic cell carcinoma. Clinicopathologic review. Cancer, 1991. 67(1): p. 172-9.

[45] Napier, S.S., B.T. Herron, and B.M. Herron, Acinic cell carcinoma in Northern Ireland: a 10-year review. The British journal of oral \& maxillofacial surgery, 1995. 33(3): 


$$
\text { p. } 145-8 \text {. }
$$

[46] Spiro, R.H. and A.G. Huvos, Stage means more than grade in adenoid cystic carcinoma. American journal of surgery, 1992. 164(6): p. 623-8.

[47] Bradley, P.J., Adenoid cystic carcinoma of the head and neck: a review. Curr Opin Otolarngol Head Neck Surg. Vol. 12. 2004: Lippincott Williams and Wilkins.

[48] Martinez-Rodriguez, N., et al., Epidemiology and treatment of adenoid cystic carcinoma of the minor salivary glands: A meta-analytic study. Medicina oral, patologia oral y cirugia bucal, 2011.

[49] Szanto, P.A., et al., Histologic grading of adenoid cystic carcinoma of the salivary glands. Cancer, 1984. 54(6): p. 1062-9.

[50] Kumar, P.P., et al., Intracranial skip metastasis from parotid and facial skin tumors: mechanism, diagnosis, and treatment. Journal of the National Medical Association, 1993. 85(5): p. 369-74.

[51] Gnepp, D.R., Malignant mixed tumors of the salivary glands: a review. Pathology annual, 1993. 28 Pt 1: p. 279-328.

[52] Nouraei, S.A., et al., Carcinoma ex benign pleomorphic adenoma of the parotid gland. Plastic and reconstructive surgery, 2005. 116(5): p. 1206-13.

[53] Zbaren, P., et al., Carcinoma ex pleomorphic adenoma: diagnostic difficulty and outcome. Otolaryngology--head and neck surgery : official journal of American Academy of Otolaryngology-Head and Neck Surgery, 2008. 138(5): p. 601-5.

[54] Damm, D.D. and J.E. Fantasia, Large palatal mass. Carcinoma ex-pleomorphic adenoma. General dentistry, 2001. 49(6): p. 574, 658.

[55] Yoshihara, T., et al., Carcinoma ex pleomorphic adenoma of the soft palate. The Journal of laryngology and otology, 1995. 109(3): p. 240-3.

[56] Antony, J., et al., Carcinoma ex Pleomorphic Adenoma: A Comprehensive Review of Clinical, Pathological and Molecular Data. Head and neck pathology, 2011.

[57] Tortoledo, M.E., M.A. Luna, and J.G. Batsakis, Carcinomas ex pleomorphic adenoma and malignant mixed tumors. Histomorphologic indexes. Archives of otolaryngology, 1984. 110(3): p. 172-6.

[58] Touquet, R., I.J. Mackenzie, and J.A. Carruth, Management of the parotid pleomorphic adenoma, the problem of exposing tumour tissue at operation. The logical pursuit of treatment policies. The British journal of oral \& maxillofacial surgery, 1990. 28(6): p. 404-8.

[59] Kwon, M.Y. and M. Gu, True malignant mixed tumor (carcinosarcoma) of parotid gland with unusual mesenchymal component: a case report and review of the literature. Archives of pathology \& laboratory medicine, 2001. 125(6): p. 812-5.

[60] Olsen, K.D. and J.E. Lewis, Carcinoma ex pleomorphic adenoma: a clinicopathologic review. Head \& neck, 2001. 23(9): p. 705-12.
[61] Luers, J.C., et al., Carcinoma ex pleomorphic adenoma of the parotid gland. Study and implications for diagnostics and therapy. Acta oncologica, 2009. 48(1): p. 132-6.

[62] Nicol, K.K. and S.S. Iskandar, Lobular carcinoma of the breast metastatic to the oral cavity mimicking polymorphous low-grade adenocarcinoma of the minor salivary glands. Archives of pathology \& laboratory medicine, 2000. 124(1): p. 157-9.

[63] Batsakis, J.G., et al., Adenocarcinomas of the oral cavity: a clinicopathologic study of terminal duct carcinomas. The Journal of laryngology and otology, 1983. 97(9): p. 825-35.

[64] Freedman, P.D. and H. Lumerman, Lobular carcinoma of intraoral minor salivary gland origin. Report of twelve cases. Oral surgery, oral medicine, and oral pathology, 1983. 56(2): p. 157-66.

[65] Pogodzinski, M.S., et al., Retrospective study and review of polymorphous low-grade adenocarcinoma. The Laryngoscope, 2006. 116(12): p. 2145-9.

[66] Zarbo, R.J., Salivary gland neoplasia: a review for the practicing pathologist. Modern pathology : an official journal of the United States and Canadian Academy of Pathology, Inc, 2002. 15(3): p. 298-323.

[67] Adornato, M.C., K. Penna, and M. Vinoski, Polymorphous low-grade adenocarcinoma of the oral cavity. The New York state dental journal, 2000. 66(5): p. 28-32.

[68] Vincent, S.D., H.L. Hammond, and M.W. Finkelstein, Clinical and therapeutic features of polymorphous lowgrade adenocarcinoma. Oral surgery, oral medicine, and oral pathology, 1994. 77(1): p. 41-7.

[69] Evans, H.L. and M.A. Luna, Polymorphous low-grade adenocarcinoma: a study of 40 cases with long-term follow up and an evaluation of the importance of papillary areas. The American journal of surgical pathology, 2000. 24(10): p. 1319-28.

[70] Seethala, R.R., et al., Polymorphous low-grade adenocarcinoma: the University of Pittsburgh experience. Archives of otolaryngology--head \& neck surgery, 2010. 136(4): p. 385-92.

[71] Simpson, R.H., et al., Polymorphous low-grade adenocarcinoma of the salivary glands with transformation to high-grade carcinoma. Histopathology, 2002. 41(3): p. 250-9.

[72] Kinnera, V.S., et al., Salivary duct carcinoma of parotid gland. Journal of oral and maxillofacial pathology : JOMFP, 2009. 13(2): p. 85-8.

[73] Lewis, J.E., et al., Salivary duct carcinoma. Clinicopathologic and immunohistochemical review of 26 cases. Cancer, 1996. 77(2): p. 223-30.

[74] Brandwein, M.S., et al., Salivary duct carcinoma (cribriform salivary carcinoma of excretory ducts). A clinicopathologic and immunohistochemical study of 12 cases. Cancer, 1990. 65(10): p. 2307-14.

[75] Chen, K.T. and G.R. Hafez, Infiltrating salivary duct carcinoma. A clinicopathologic study of five cases. Archives of otolaryngology, 1981. 107(1): p. 37-9. 
[76] Delgado, R., F. Vuitch, and J. Albores-Saavedra, Salivary duct carcinoma. Cancer, 1993. 72(5): p. 1503-12.

[77] Colmenero Ruiz, C., M. Patron Romero, and M. Martin Perez, Salivary duct carcinoma: a report of nine cases. Journal of oral and maxillofacial surgery : official journal of the American Association of Oral and Maxillofacial Surgeons, 1993. 51(6): p. 641-6.

[78] Simpson, R.H., et al., Salivary duct adenocarcinoma. Histopathology, 1991. 18(3): p. 229-35.

[79] Auclair PL, E.C.A.P., Ellis CL. , Adenocarcinoma, not otherwise specified. Surgical Pathology of the Salivary Glands. , ed. A.P. Ellis GL, Gnepp DR, eds.1991, Philadelphia, Pa: WB Saunders Co.

[80] van der Wal, J.E., et al., Parotid gland tumors: histologic reevaluation and reclassification of 478 cases. Head \& neck, 1998. 20(3): p. 204-7.

[81] O'Brien, C.J., V.B. Malka, and M. Mijailovic, Evaluation of 242 consecutive parotidectomies performed for benign and malignant disease. The Australian and New Zealand journal of surgery, 1993. 63(11): p. 870-7.

[82] O'Hara, J., et al., Cutaneous squamous cell carcinoma of the head and neck metastasizing to the parotid gland-A review of current recommendations. Head \& neck, 2010.

[83] Guillamondegui, O.M., Salivary gland cancers, surgery, and irradiation therapy. Archives of otolaryngology, 1982. 108(11): p. 709.

[84] Lee, S., et al., Primary squamous cell carcinoma of the parotid gland. American journal of otolaryngology, 2001. 22(6): p. $400-6$

[85] Batsakis, J.G., et al., Primary squamous cell carcinoma of the parotid gland. Archives of otolaryngology, 1976. 102(6): p. 355-7.

[86] Ying, Y.L., J.T. Johnson, and E.N. Myers, Squamous cell carcinoma of the parotid gland. Head \& neck, 2006. 28(7): p. 626-32.

[87] Marshak, G. and O. Leitner, Cytokeratin polypeptides in normal and metaplastic human salivary gland epithelia. Journal of oral pathology, 1987. 16(9): p. 442-9.

[88] Okura, M., et al., Expression of S-100 protein and glial fibrillary acidic protein in cultured submandibular gland epithelial cells and salivary gland tissues. Histogenetic implication for salivary gland tumors. The American journal of pathology, 1996. 148(5): p. 1709-16.

[89] Draeger, A., et al., Cytokeratins, smooth muscle actin and vimentin in human normal salivary gland and pleomorphic adenomas. Immunohistochemical studies with particular reference to myoepithelial and basal cells. APMIS : acta pathologica, microbiologica, et immunologica Scandinavica, 1991. 99(5): p. 405-15.

[90] He, H., et al., A joint detection of CEA and CA-50 levels in saliva and serum of patients with tumors in oral region and salivary gland. Journal of cancer research and clinical oncology, 2009. 135(10): p. 1315-21.

[91] Holst, V.A., et al., KIT protein expression and analysis of $c$ - kit gene mutation in adenoid cystic carcinoma. Modern pathology : an official journal of the United States and Canadian Academy of Pathology, Inc, 1999. 12(10): p. 95660.

[92] Tetsu, O., et al., Mutations in the c-Kit gene disrupt mitogen-activated protein kinase signaling during tumor development in adenoid cystic carcinoma of the salivary glands. Neoplasia, 2010. 12(9): p. 708-17.

[93] Jeng, Y.M., C.Y. Lin, and H.C. Hsu, Expression of the c-kit protein is associated with certain subtypes of salivary gland carcinoma. Cancer letters, 2000. 154(1): p. 107-11.

[94] Curran, A.E., et al., Distinctive pattern of glial fibrillary acidic protein immunoreactivity useful in distinguishing fragmented pleomorphic adenoma, canalicular adenoma and polymorphous low grade adenocarcinoma of minor salivary glands. Head and neck pathology, 2007. 1(1): p. 2732.

[95] Curran, A.E., et al., Polymorphous low-grade adenocarcinoma versus pleomorphic adenoma of minor salivary glands: resolution of a diagnostic dilemma by immunohistochemical analysis with glial fibrillary acidic protein. Oral surgery, oral medicine, oral pathology, oral radiology, and endodontics, 2001. 91(2): p. 194-9.

[96] Scianna, J.M. and G.J. Petruzzelli, Contemporary management of tumors of the salivary glands. Current oncology reports, 2007. 9(2): p. 134-8.

[97] Day, T.A., et al., Salivary gland neoplasms. Current treatment options in oncology, 2004. 5(1): p. 11-26.

[98] Gates, G.A., Current concepts in otolaryngology: malignant neoplasms of the minor salivary glands. The New England journal of medicine, 1982. 306(12): p. 718-22.

[99] Wong, D.S. and G.K. Li, The role of fine-needle aspiration cytology in the management of parotid tumors: a critical clinical appraisal. Head \& neck, 2000. 22(5): p. 469-73.

[100] Sismanis, A., et al., Diagnosis of salivary gland tumors by fine needle aspiration biopsy. Head \& neck surgery, 1981. 3(6): p. 482-9.

[101] Kechagias, N., et al., Fine-needle aspiration cytology of salivary gland tumours: a 10-year retrospective analysis. Oral and maxillofacial surgery, 2011.

[102] Cohen, E.G., et al., Fine-needle aspiration biopsy of salivary gland lesions in a selected patient population. Archives of otolaryngology--head \& neck surgery, 2004. 130(6): p. 773-8.

[103] Jayaram, N., et al., The value of fine-needle aspiration biopsy in the cytodiagnosis of salivary gland lesions. Diagnostic cytopathology, 1989. 5(4): p. 349-54.

[104] Cardillo, M.R., Salivary gland masses: the diagnostic value of fine-needle aspiration cytology. Archives d'anatomie et de cytologie pathologiques, 1990. 38(1-2): p. 26-32.

[105] Megerian, C.A. and A.J. Maniglia, Parotidectomy: a ten year experience with fine needle aspiration and frozen section biopsy correlation. Ear, nose, \& throat journal, 1994. 73(6): p. 377-80. 
[106] Stewart, C.J., et al., Fine-needle aspiration cytology of salivary gland: a review of 341 cases. Diagnostic cytopathology, 2000. 22(3): p. 139-46.

[107] Alphs, H.H., D.W. Eisele, and W.H. Westra, The role of fine needle aspiration in the evaluation of parotid masses. Current opinion in otolaryngology \& head and neck surgery, 2006. 14(2): p. 62-6.

[108] Seethala, R.R., V.A. LiVolsi, and Z.W. Baloch, Relative accuracy of fine-needle aspiration and frozen section in the diagnosis of lesions of the parotid gland. Head \& neck, 2005. 27(3): p. 217-23.

[109] Cho, H.W., et al., Sonographically guided fine-needle aspiration biopsy of major salivary gland masses: a review of 245 cases. AJR. American journal of roentgenology, 2011. 196(5): p. 1160-3.

[110] Mighell, A.J. and A.S. High, Histological identification of carcinoma in 21 gauge needle tracks after fine needle aspiration biopsy of head and neck carcinoma. Journal of clinical pathology, 1998. 51(3): p. 241-3.

[111] Moloo, Z., et al., Possible spread of bronchogenic carcinoma to the chest wall after a transthoracic fine needle aspiration biopsy. A case report. Acta cytologica, 1985. 29(2): p. $167-9$

[112] Roussel, F., J. Dalion, and M. Benozio, The risk of tumoral seeding in needle biopsies. Acta cytologica, 1989. 33(6): p. 936-9.

[113] Brennan, P.A., et al., Fine needle aspiration cytology (FNAC) of salivary gland tumours: repeat aspiration provides further information in cases with an unclear initial cytological diagnosis. The British journal of oral \& maxillofacial surgery, 2010. 48(1): p. 26-9.

[114] Riley, N., R. Allison, and S. Stevenson, Fine-needle aspiration cytology in parotid masses: our experience in Canterbury, New Zealand. ANZ journal of surgery, 2005. 75(3): p. 144-6.

[115] Carrillo, J.F., et al., Diagnostic accuracy of fine needle aspiration biopsy in preoperative diagnosis of patients with parotid gland masses. Journal of surgical oncology, 2009. 100(2): p. 133-8.

[116] Cross, D.L., T.S. Gansler, and R.C. Morris, Fine needle aspiration and frozen section of salivary gland lesions. Southern medical journal, 1990. 83(3): p. 283-6.

[117] Westra, W.H., Diagnostic difficulties in the classification and grading of salivary gland tumors. International journal of radiation oncology, biology, physics, 2007. 69(2 Suppl): p. S49-51.

[118] Das, D.K., et al., Role of fine needle aspiration cytology in the diagnosis of swellings in the salivary gland regions: a study of 712 cases. Medical principles and practice : international journal of the Kuwait University, Health Science Centre, 2004. 13(2): p. 95-106.

[119] Wong, D.S., Frozen section during parotid surgery revisited: efficacy of its applications and changing trend of indications. Head \& neck, 2002. 24(2): p. 191-7.

[120] Iwai, H., et al., [Evaluation of frozen section diagnosis of parotid gland tumors]. Nihon Jibiinkoka Gakkai kaiho, 1999. 102(11): p. 1227-33.

[121] Carvalho, M.B., et al., Perioperative frozen section examination in parotid gland tumors. Sao Paulo medical journal $=$ Revista paulista de medicina, 1999. 117(6): p. 233-7.

[122] Zheng, J.W., X.Y. Song, and X.G. Nie, The accuracy of clinical examination versus frozen section in the diagnosis of parotid masses. Journal of oral and maxillofacial surgery : official journal of the American Association of Oral and Maxillofacial Surgeons, 1997. 55(1): p. 29-31; discussion 32.

[123] Arabi Mianroodi, A.A., E.A. Sigston, and N.A. Vallance, Frozen section for parotid surgery: should it become routine? ANZ journal of surgery, 2006. 76(8): p. 736-9.

[124]Edge S, B.D., Compton C, et al., AJCC Cancer Staging Manual. 7th ed2010: Springer.

[125] Lamont, J.P., et al., Prospective evaluation of office-based parotid ultrasound. Annals of surgical oncology, 2001. 8(9): p. $720-2$.

[126] Corr, P., P. Cheng, and C. Metreweli, The role of ultrasound and computed tomography in the evaluation of parotid masses. Australasian radiology, 1993. 37(2): p. 195-7.

[127] Whyte, A.M. and J.V. Byrne, A comparison of computed tomography and ultrasound in the assessment of parotid masses. Clinical radiology, 1987. 38(4): p. 339-43.

[128] Jeong, H.S., et al., Role of 18F-FDG PET/CT in management of high-grade salivary gland malignancies. Journal of nuclear medicine : official publication, Society of Nuclear Medicine, 2007. 48(8): p. 1237-44.

[129] Som, P.M. and H.F. Biller, High-grade malignancies of the parotid gland: identification with MR imaging. Radiology, 1989. 173(3): p. 823-6.

[130] Swartz, J.D., et al., MR imaging of parotid mass lesions: attempts at histopathologic differentiation. Journal of computer assisted tomography, 1989. 13(5): p. 789-96.

[131] Yousem, D.M., M.A. Kraut, and A.A. Chalian, Major salivary gland imaging. Radiology, 2000. 216(1): p. 19-29.

[132] Teresi, L.M., et al., Parotid masses: MR imaging. Radiology, 1987. 163(2): p. 405-9.

[133] Yabuuchi, H., et al., Salivary gland tumors: diagnostic value of gadolinium-enhanced dynamic $M R$ imaging with histopathologic correlation. Radiology, 2003. 226(2): p. 345-54.

[134] Nowak, B., et al., Diagnostic evaluation of malignant head and neck cancer by F-18-FDG PET compared to CT/MRI. Nuklearmedizin. Nuclear medicine, 1999. 38(8): p. 312-8.

[135] Uchida, Y., et al., Diagnostic value of FDG PET and salivary gland scintigraphy for parotid tumors. Clinical nuclear medicine, 2005. 30(3): p. 170-6.

[136] McGuirt, W.F., et al., Preoperative identification of benign versus malignant parotid masses: a comparative study including positron emission tomography. The Laryngoscope, 1995. 105(6): p. 579-84. 
[137] Myers, E.N., Suen, J.Y, eds, Cancer of the Head and neck1996, Philadelphia: Saunders.

[138] Iseli, T.A., et al., Outcomes of static and dynamic facial nerve repair in head and neck cancer. The Laryngoscope, 2010. 120(3): p. 478-83.

[139] Tabb, H.G., A.N. Scalco, and S.F. Fraser, Exposure of the facial nerve in parotid surgery. (Use of the tympanomastoid fissure as a guide). The Laryngoscope, 1970. 80(4): p. 55967.

[140] Pather, N. and M. Osman, Landmarks of the facial nerve: implications for parotidectomy. Surgical and radiologic anatomy: SRA, 2006. 28(2): p. 170-5.

[141] Beahrs, O.H. and B.F. L'Esperance, The facial nerve in parotid surgery. Journal of the American Medical Association, 1956. 162(4): p. 261-3.

[142] Toure, G. and C. Vacher, Relations of the facial nerve with the retromandibular vein: anatomic study of 132 parotid glands. Surgical and radiologic anatomy : SRA, 2010. 32(10): p. 957-61.

[143] de Ru, J.A., et al., Landmarks for parotid gland surgery. The Journal of laryngology and otology, 2001. 115(2): p. 122-5.

[144] Reid, A.P., Surgical approach to the parotid gland. Ear, nose, $\&$ throat journal, 1989. 68(2): p. 151-4.

[145] Conley, J., Search for and identification of the facial nerve. The Laryngoscope, 1978. 88(1 Pt 1): p. 172-5.

[146] Conley, J. and R.C. Hamaker, Prognosis of malignant tumors of the parotid gland with facial paralysis. Archives of otolaryngology, 1975. 101(1): p. 39-41.

[147] de Ru, J.A., et al., Preoperative determination of the location of parotid gland tumors by analysis of the position of the facial nerve. Journal of oral and maxillofacial surgery : official journal of the American Association of Oral and Maxillofacial Surgeons, 2001. 59(5): p. 525-8; discussion 529-30.

[148] Beahrs, O.H., The surgical anatomy and technique of parotidectomy. The Surgical clinics of North America, 1977. 57(3): p. 477-93.

[149] Corlette, T.H., et al., Neck dissection of level IIb: is it really necessary? The Laryngoscope, 2005. 115(9): p. 1624-6.

[150] Schramm, V.L., Jr. and M.J. Imola, Management of nasopharyngeal salivary gland malignancy. The Laryngoscope, 2001. 111(9): p. 1533-44.

[151] Bensadoun, R.J., et al., [2003 update of Standards, Options and Recommandations for radiotherapy for patients with salivary gland malignant tumors (excluding lymphona, sarcoma and melanoma)]. Cancer radiotherapie : journal de la Societe francaise de radiotherapie oncologique, 2003. 7(4): p. $280-95$.

[152] Armstrong, J.G., et al., Malignant tumors of major salivary gland origin. A matched-pair analysis of the role of combined surgery and postoperative radiotherapy. Archives of otolaryngology--head \& neck surgery, 1990. 116(3): p. 290-3.

[153] Harrison, L.B., et al., Postoperative radiation therapy for major salivary gland malignancies. Journal of surgical oncology, 1990. 45(1): p. 52-5.

[154] Garden, A.S., et al., Postoperative radiotherapy for malignant tumors of the parotid gland. International journal of radiation oncology, biology, physics, 1997. 37(1): p. 7985

[155] Fu, K.K., et al., Carcinoma of the major and minor salivary glands: analysis of treatment results and sites and causes of failures. Cancer, 1977. 40(6): p. 2882-90.

[156] Guillamondegui, O.M., et al., Aggressive surgery in treatment for parotid cancer: the role of adjunctive postoperative radiotherapy. The American journal of roentgenology, radium therapy, and nuclear medicine, 1975. 123(1): p. 49-54.

[157] Terhaard, C.H., et al., The role of radiotherapy in the treatment of malignant salivary gland tumors. International journal of radiation oncology, biology, physics, 2005. 61(1): p. $103-11$

[158] Mendenhall, W.M., et al., Radiotherapy alone or combined with surgery for salivary gland carcinoma. Cancer, 2005. 103(12): p. 2544-50

[159] Chen, A.M., et al., Local-regional recurrence after surgery without postoperative irradiation for carcinomas of the major salivary glands: implications for adjuvant therapy. International journal of radiation oncology, biology, physics, 2007. 67(4): p. 982-7.

[160] Garden, A.S., et al., The influence of positive margins and nerve invasion in adenoid cystic carcinoma of the head and neck treated with surgery and radiation. International journal of radiation oncology, biology, physics, 1995. 32(3): p. $619-26$

[161] Storey, M.R., et al., Postoperative radiotherapy for malignant tumors of the submandibular gland. International journal of radiation oncology, biology, physics, 2001. 51(4): p. $952-8$.

[162] Laramore, G.E., et al., Neutron versus photon irradiation for unresectable salivary gland tumors: final report of an RTOG-MRC randomized clinical trial. Radiation Therapy Oncology Group. Medical Research Council. International journal of radiation oncology, biology, physics, 1993. 27(2): p. 235-40.

[163] Huber, P.E., et al., Radiotherapy for advanced adenoid cystic carcinoma: neutrons, photons or mixed beam? Radiotherapy and oncology : journal of the European Society for Therapeutic Radiology and Oncology, 2001. 59(2): p. 161-7.

[164] Rentschler, R., M.A. Burgess, and R. Byers, Chemotherapy of malignant major salivary gland neoplasms: a 25-year review of M. D. Anderson Hospital experience. Cancer, 1977. 40(2): p. 619-24.

[165] Licitra, L., et al., Cisplatin in advanced salivary gland carcinoma. A phase II study of 25 patients. Cancer, 1991. 68(9): p. 1874-7.

[166] Vermorken, J.B., et al., Epirubicin in patients with advanced or recurrent adenoid cystic carcinoma of the head and neck: a phase II study of the EORTC Head and Neck Cancer 
Cooperative Group. Annals of oncology : official journal of the European Society for Medical Oncology / ESMO, 1993. 4(9): p. 785-8.

[167] Airoldi, M., et al., Phase II randomized trial comparing vinorelbine versus vinorelbine plus cisplatin in patients with recurrent salivary gland malignancies. Cancer, 2001. 91(3): p. 541-7.

[168] Haddad, R., et al., Herceptin in patients with advanced or metastatic salivary gland carcinomas. A phase II study. Oral oncology, 2003. 39(7): p. 724-7.

[169] Airoldi, M., et al., Paclitaxel and carboplatin for recurrent salivary gland malignancies. Anticancer research, 2000. 20(5C): p. 3781-3.

[170] Cajulis, R.S., et al., Fine needle aspiration biopsy of the salivary glands. A five-year experience with emphasis on diagnostic pitfalls. Acta cytologica, 1997. 41(5): p. 1412-20.

[171] Al-Khafaji, B.M., B.R. Nestok, and R.L. Katz, Fine-needle aspiration of 154 parotid masses with histologic correlation: ten-year experience at the University of Texas M. D. Anderson Cancer Center. Cancer, 1998. 84(3): p. 153-9.

[172] Tan, L.G. and M.L. Khoo, Accuracy of fine needle aspiration cytology and frozen section histopathology for lesions of the major salivary glands. Annals of the Academy of Medicine, Singapore, 2006. 35(4): p. 242-8.

[173] Tew, S., A.G. Poole, and J. Philips, Fine-needle aspiration biopsy of parotid lesions: comparison with frozen section. The Australian and New Zealand journal of surgery, 1997. 67(7): p. 438-41

[174] Umapathy, N., et al., Performance of parotidectomy in nonspecialist centers. Archives of otolaryngology--head \& neck surgery, 2003. 129(9): p. 925-8; discussion 928.

[175] Bova, R., A. Saylor, and W.B. Coman, Parotidectomy: review of treatment and outcomes. ANZ journal of surgery, 2004. 74(7): p. 563-8.

[176] Gaillard, C., et al., Facial nerve dysfunction after parotidectomy: the role of local factors. The Laryngoscope, 2005. 115(2): p. 287-91.
[177] Eng, C.Y., et al., A comparison of the incidence of facial palsy following parotidectomy performed by ENT and nonENT surgeons. The Journal of laryngology and otology, 2007. 121(1): p. 40-3.

[178] Roh, J.L. and C.I. Park, A prospective, randomized trial for use of prednisolone in patients with facial nerve paralysis after parotidectomy. American journal of surgery, 2008. 196(5): p. 746-50.

[179] Klintworth, N., et al., Postoperative complications after extracapsular dissection of benign parotid lesions with particular reference to facial nerve function. The Laryngoscope, 2010. 120(3): p. 484-90.

[180] Mahmood, K., G.S. Williams, and N. Morgan, Postparotidectomy facial nerve paralysis: peripheral versus proximal identification. B-ENT, 2010. 6(2): p. 117-21.

[181] Fitzpatrick, P.J. and C. Theriault, Malignant salivary gland tumors. International journal of radiation oncology, biology, physics, 1986. 12(10): p. 1743-7.

[182] Tran, L., et al., Major salivary gland tumors: treatment results and prognostic factors. The Laryngoscope, 1986. 96(10): p. 1139-44.

[183] Frankenthaler, R.A., et al., Prognostic variables in parotid gland cancer. Archives of otolaryngology--head \& neck surgery, 1991. 117(11): p. 1251-6.

[184] Mendenhall, W.M., et al., Radiotherapy alone or combined with surgery for adenoid cystic carcinoma of the head and neck. Head \& neck, 2004. 26(2): p. 154-62.

[185] Pohar, S., et al., Malignant parotid tumors: presentation, clinical/pathologic prognostic factors, and treatment outcomes. International journal of radiation oncology, biology, physics, 2005. 61(1): p. 112-8.

[186] Chen, A.M., et al., Adenoid cystic carcinoma of the head and neck treated by surgery with or without postoperative radiation therapy: prognostic features of recurrence. International journal of radiation oncology, biology, physics, 2006. 66(1): p. 152-9. 